tion for publication bias. Moreover, the odds ratio outcome was used exclusively in this investigation. The appearance of a funnel plot can depend on the outcome measure used, and different results might be obtained in some instances if the risk difference or relative risk scale is used. The sensitivity of assessments of publication bias to the outcome measure used requires further investigation.

The idea of adjusting the results of meta-analyses for publication bias and imputing "fictional" studies into a meta-analysis is controversial. ${ }^{15}$ We certainly would not rely on results of imputed studies in forming a final conclusion, partly because asymmetry in a funnel plot may be due to factors other than publication bias. Any adjustment method should be used primarily as a form of sensitivity analysis, to assess the potential effect of missing studies on the meta-analysis, rather than as a means of adjusting results themselves.

If, as our study indicates, missing studies change the conclusions in less than $10 \%$ of meta-analyses, publication bias, although widespread, may not be a major practical problem. On the other hand, the fact that almost half the funnel plots examined seemed to exhibit some asymmetry leads us to conclude that routine evaluation for this bias should be an important step in any systematic review.

Contributors: AJS had the original idea for the study, extracted the relevant data from the Cochrane Database of Systematic Reviews, and assisted with the interpretation of the results. SJD assisted with the study design, carried out the trim and fill analyses, and assisted with the interpretation of the results. RLT assisted with the study design and the interpretation of the results. KRA and DRJ assisted with the interpretation of the results. The paper was written and revised jointly by all authors AJS is the guarantor for this paper.

Funding: None.

Competing interests: None declared.

1 Song F, Easterwood A, Gilbody S, Duley L, Sutton, AJ. Publication bias. In Stevens A, Abrams K, Brazier J, Fitzpatrick R, Lilford R, eds. Handbook of research methods for evidence-based health care-insights from the NHS HTA programme. London: Sage Publications (in press).

2 Horton R. Medical editors trial amnesty. Lancet 1997;350:756

3 Easterbrook PJ. Directory of registries of clinical trials. Stat Med 1992;11:345-423.

\section{What is already known on this topic}

Meta-analyses are subject to bias because smaller or non-significant studies are less likely to be published

Most meta-analyses do not consider the effect of publication bias on their results

\section{What this study adds}

A simple trim and fill adjustment method on studies in the Cochrane database suggests that publication bias may be present to some degree in about $50 \%$ of meta-analyses and strongly indicated in about $20 \%$

Publication bias affected the results in less than $10 \%$ of meta-analyses

Researchers should always check for the presence of publication bias and perform a sensitivity analysis to assess the potential impact of missing studies

4 Begg CB. Publication bias. In: Cooper H, Hedges LV, eds. The handbook of research synthesis. New York: Russell Sage Foundation, 1994:399-409.

5 Begg CB, Mazumdar M. Operating characteristics of a rank correlation test for publication bias. Biometrics 1994;50:1088-101.

6 Egger M, Smith GD, Schneider M, Minder C. Bias in meta-analysis detected by a simple, graphical test. BMJ 1997;315:629-34.

7 Tallon D, Schneider M, Egger M. Quality of systematic reviews published in high impact general and specialist journals. Proceedings of 2nd symposium on systematic reviews: beyond the basics, Oxford, 1999. (www.ihs.ox.ac.uk/csm/talks.html\#p8; accessed 1 June 2000.)

8 Linde K, Clausius N, Ramirez G, Melchart D, Eitel F, Hedges LV, et al. Are the clinical effects of homoeopathy placebo effects? A meta-analysis of placebo-controlled trials. Lancet 1997;350:834-43.

9 Cochrane database of systematic reviews. In: Cochrane Collaboration Cochrane Library. Issue 3. Oxford: Update Software, 1998.

10 Duval S, Tweedie R. Practical estimates of the effect of publication bias in meta-analysis. Australasian Epidemiologist 1998;5:14-7.

11 Duval S, Tweedie R. A non-parametric "trim and fill" method of assessing publication bias in meta-analysis. J Am Stat Ass (in press).

12 Duval S, Tweedie R. Trim and fill: a simple funnel plot based method of testing and adjusting for publication bias in meta-analysis. Biometrics (in press).

13 Sankey SS, Weissfeld LA, Fine MJ, Kapoor W. An assessment of the use of the continuity correction for sparse data in meta-analysis. Communication In Statistics-Simulation and Computation 1996;25:1031-56.

14 Petticrew M, Gilbody S, Sheldon TA. Relation between hostility and coronary heart disease: evidence does not support link. BMJ 1999;319:917.

15 Begg CB. Comment on Givens GH, Smith DD, Tweedie RL. Publication bias in meta-analysis: a Bayesian data-augmentation approach to account for issues exemplified in the passive smoking debate. Stat Sci 1997;12:221-50.

(Accepted 2 March 2000)

\title{
Back pain in Britain: comparison of two prevalence surveys at an interval of 10 years
}

\author{
Keith T Palmer, Kevin Walsh, Holly Bendall, Cyrus Cooper, David Coggon
}

In Britain, as in many other countries, back pain is a major cause of disability, especially in adults of working age. During the decade to 1993, outpatient attendances for back pain rose fivefold, and the number of days of incapacity from back disorders for which social security benefits were paid more than doubled. ${ }^{1}$ It is unclear whether this represents an increase in the occurrence of diseases affecting the back or a change in people's behaviour when they have symptoms. To address this question we compared the prevalence of low back pain and associated disability in two postal surveys 10 years apart.

\section{Subjects, methods, and results}

Both surveys were approved by the relevant local ethics committees. The first was conducted during 1987-8 and obtained information from 2667 men and women randomly selected from the lists of 136 general practitioners in eight geographically dispersed locations in Britain (59\% response rate). ${ }^{2}$ Of these, 2596 were aged 20-59 years at the time of completing the questionnaire. The investigation focused on occupational and other risk factors for back symptoms and included a question about the occurrence of back pain that had
Editorial by Croft

Correspondence to: D Coggon dnc@mrc.soton.ac.uk continued over BMJ 2000;320:1577-8 
One year prevalence ${ }^{\star}$ of symptoms of low back pain in 1987-8 and 1997-8 in patients randomly selected from general practitioners' lists. Values are numbers (percentages) of patients unless indicated otherwise

Men

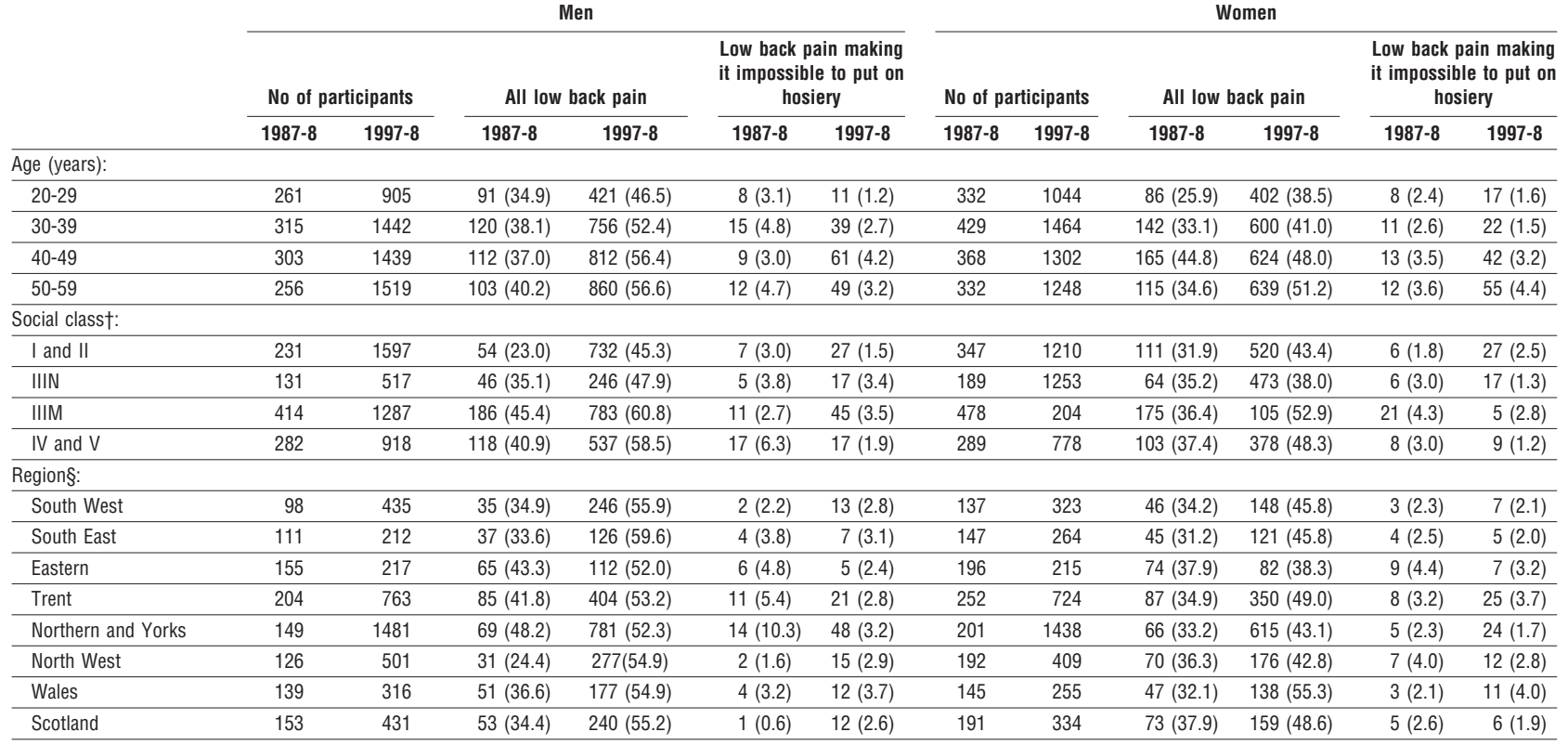

*Prevalence by social class and region was directly standardised to the age distribution of the combined samples from both surveys.

†In 1987-8 the social class of married women was classified according to their husband's occupation. In all other cases social class was based on the subject's own occupation. Social class could not be classified for 235 subjects in 1987-8 and 2599 subjects in 1997-8.

$\S$ Prevalence by region is presented for those regions that included towns surveyed in 1987-8. Because the sampling within each region was geographically localised, these rates may not be representative of those in the region as a whole.

MRC

Environmental

Epidemiology Unit,

Community

Clinical Sciences,

University of

Southampton,

Southampton

SO16 6YD

Keith T Palmer

clinical scientist

Holly Bendall

medical statistician

David Coggon

professor of

occupational and

environmental

medicine

MRC

Environmental

Epidemiology Unit,

Fetal Origins of

Adult Disease,

University of

Southampton

Cyrus Cooper

professor of

rheumatology

Hinchingbrooke

Hospital,

Huntingdon

PE18 8NT

Kevin Walsh

consultant

geriatrician lasted for 24 hours or longer during the previous 12 months in an area between the 12th ribs and the gluteal folds (illustrated with a diagram). Those who reported the symptom were asked whether it had made it impossible to put on hosiery (socks, stockings, or tights).

In the second survey, conducted during 1997-8, questionnaires were completed by 10363 men and women aged 20-59 years who were chosen at random from the lists of 163 general practitioners across Britain (57\% response rate). ${ }^{3}$ This study was designed to assess occupational exposure to vibration and associated health effects and included the same questions about back pain as the earlier investigation.

Over the 10 year interval between the two surveys, the one year prevalence of back pain (directly standardised to the age and sex distribution of the combined samples) rose from $36.4 \%$ to $49.1 \%$ (95\% confidence interval for difference $10.6 \%$ to $15.1 \%)$. The trend was consistent across all ages in both men and women, and also within social classes and regions (see table). In contrast, the age and sex standardised prevalence of back pain that made it impossible to put on hosiery fell by $0.7 \%(-0.1 \%$ to $1.5 \%)$.

\section{Comment}

Over a 10 year interval the one year prevalence of back pain rose by $12.7 \%$, but with no increase in the prevalence of symptoms sufficient to prevent people putting on hosiery. This suggests that the rise in outpatient attendances and sickness absence for back disorders is not explained by a greater incidence of severe back disease. We did, however, find a marked increase in the prevalence of less disabling back pain.
The surveys analysed were based on large samples selected in an identical manner, with wide geographical coverage and similar response rates. It is unlikely that the change can be explained by bias or chance. There may have been an increase in back disorders that do not greatly impair spinal flexion, but a more likely explanation is that cultural changes have led to a greater awareness of more minor back symptoms and willingness to report them, and this cultural shift may also have rendered back pain more acceptable as a reason for absence attributed to sickness. ${ }^{4}$ If this is correct, the solution to the growing economic burden from back pain may lie more in modifying people's attitudes and behaviour than in interventions aimed at reducing physical stresses on the spine.

We thank the general practitioners who allowed us to approach their patients, and Ian Bowes and Vanessa Cox for their help with the data preparation.

Contributors: KTP designed and carried out the second survey. KW designed and carried out the first survey. $\mathrm{HB}$ carried out the statistical analysis. CC helped to plan the second survey and the statistical analysis. DC supervised both surveys, wrote the first draft of the paper, and is the guarantor of the work. All authors helped to edit the paper.

Funding: The contribution of $\mathrm{KW}$ to this research was supported by a fellowship provided by Esso UK plc. The second survey was funded by the Health and Safety Executive.

Competing interests: None declared.

1 Clinical Standards Advisory Group. Epidemiology review: the epidemiology and cost of back pain. London: HMSO, 1994.

2 Walsh K, Cruddas M, Coggon D. Low back pain in eight areas of Britain. J Epidemiol Comm Health 1992;46:227-30.

3 Palmer KT, Coggon D, Bendall HE, Pannett B, Griffin MJ, Haward BM. Whole-body vibration: occupational exposures and their health effects in Great Britain. London: HMSO, 1999. (HSE contract research report 233/1999.)

4 Chew CA, May CR. The benefits of back pain. Fam Pract 1997;14:461-5.

(Accepted 22 February 2000) 